\title{
CARACTERIZAÇÃO AMBIENTAL DA BACIA HIDROGRÁFICA DO RIO MUNIN
}

\author{
Joyce Maria Silva Costa - joy-nike@ hotmail.com \\ Universidade Ceuma
}

Mikaelle Luzia Silva Dutra - mickaelle.silva@live.com

Universidade Ceuma

Arisson Tyson Machado Buna - arissonbuna@ hotmail.com

Universidade Ceuma

Juliana Lopes Almeida - july01.j1@ gmail.com

Universidade Ceuma

Juliana Martins dos Santos - julianamartins007@ hotmail.com

Universidade Ceuma

Eliane do Santos Gomes - elianezdm@hotmail.com

Universidade Ceuma

Prof. Dr. Fabrício Brito Silva - fabricioagro@gmail.com

Universidade Ceuma 


\section{Resumo}

A Bacia Hidrográfica do Rio Munin possui uma área de $15.817,4 \mathrm{~km}^{2}$, localiza-se no nordeste do estado do Maranhão, tendo sua nascente no município de Aldeias Altas e sua foz na baía de São José entre os municípios de Axixá e Icatú. Este trabalho teve como objetivo a caracterização ambiental da bacia hidrográfica do Rio Munin. Inicialmente, a bacia foi delimitada utilizando dados do sensor SRTM (Shuttle Radar Topography Mission) e técnicas de geoprocessamento. Após a delimitação da bacia, foram extraídos os seguintes aspectos: geologia, geomorfologia, os solos e vegetação. Para a caracterização dos dados, primeiramente, foram utilizadas imagens SRTM no formato geotiff, oriundos da base de dados USGS. Os dados referentes as características ambientais que abrangem a área da Bacia Hidrográfica foram obtidas através do IBGE e CPRM (Companhia de Pesquisa de Recursos Minerais). Os resultados mostraram que a geomorfologia do local apresenta uma diversidade de formas separadas em sete unidades, com a predominância do Panamá do Rio Itapecuru e Tabuleiros Costeiros. O solo apresentou uma variedade de sete tipos de solos, com predominância do Plintossolo Pétrico e Concrecionário Distrófico. A vegetação na região apresentou um total de onze tipos, com predominância da Savana/ Floresta Estacional, Vegetação Secundária e Atividades Agrárias. A geologia apresentou uma diversidade que totalizou onze unidades, com a predominância de Itapecuru. Os aspectos estudados possibilitaram uma caracterização ambiental geral da Bacia Hidrográfica do Rio Munin, gerando dados que possam ser utilizados posteriormente para futuros estudos desta área.

Palavras-Chaves: Descrição ambiental, Bacia hidrográfica, Geoprocessamento.

\section{Introdução}

A bacia hidrográfica é considerada uma unidade de estudo (Política Nacional de Recursos Hídricos, 9.433/97) e, também referência na análise da paisagem, pois possibilita reconhecer os diversos elementos e os processos que atuam na modificação da modelagem terrestre, em nível local, por intermédio da dinâmica estabelecida na troca de energia e matéria.

Entende-se por bacia hidrográfica ou bacia de contribuição uma área delimitada topograficamente num ponto do percurso de água, de maneira que toda a vazão afluente possa ser medida através desse ponto (GARCEZ; ALVAREZ, 1988, p. 43). Dessa forma, elas funcionam como uma coletora de águas pluviais e fluviais, configurando um 
importante instrumento para o planejamento e caracterização ambiental, garantindo o equilíbrio entre os diferentes ecossistemas. Sendo assim, o sensoriamento remoto é uma importante ferramenta de obtenção de informações que por meio de sensores mensuram os aspectos terrestres, auxiliando na caracterização das bacias hidrográficas.

Conforme a resolução $\mathrm{n}^{\circ}$ 32, de 25 junho de 2003, o Conselho Nacional de Recursos Hídricos, o território brasileiro está dividido em doze regiões hidrográficas. Nesse aspecto o estado do Maranhão localiza-se em apenas três regiões: região hidrográfica do Atlântico Nordeste Ocidental, Região Hidrográfica do Parnaíba e região hidrográfica do Tocantins/Araguaia.

O Maranhão possui um conjunto de 12 bacias hidrográfica com rios perenes o ano inteiro, ou seja, inexiste um cenário de seca, sendo o único Estado do Nordeste que não faz parte do semiárido brasileiro, caracteriza-se pelo seu grande potencial hídrico, devido ao local de transição inserido, apresenta uma situação única no que diz respeito a esses recursos. Esse, por sua vez, ameaçados por ocupação das margens dos rios, grandes investimentos implantados sem planejamento adequado, desordenada extração mineral com elevado índices de desmatamentos e queimadas, despejos de esgotos dentre outras atividades prejudicais na manutenção da bacia.

Ao estudar as questões hídricas apenas com o foco na escassez de água tende a ser uma vertente simplista, e não atende ao pressuposto da diversidade desafiadora dos aspectos das águas previsto na Lei Federal 9443/97 (IV, Art. 1). Para que a alegação dos usos múltiplos seja devidamente atendida, para que as situações de escassez hídrica possam ser gerenciadas mais adequadamente, a Política Nacional de Recursos Hídricos (PNRH) estabeleceu através da "Lei das Águas" (Lei 9443/97), onde a gestão de recursos hídricos tem a bacia hidrográfica como unidade de planejamento, sendo assim torna-se necessário conhecer mais profundamente os aspectos geomorfológicos, geológicos, vegetação e solo

A qualidade ambiental dos recursos hídricos em nosso país vem sendo ameaçada por interferências antrópicas reflexo do modelo de desenvolvimento da sociedade contemporânea. $\mathrm{O}$ presente trabalho teve como objetivo a caracterização ambiental da bacia hidrográfica do Rio Munim através do sensoriamento remoto, gerando dados que possam ser utilizados posteriormente para futuros estudos desta área. 


\section{Metodologia}

A Bacia Hidrográfica do Rio Munin localiza-se no nordeste do estado do Maranhão, tendo sua nascente no município de Aldeias Altas e sua foz na baía de São José entre os municípios de Axixá e Icatú. Inicialmente, a bacia foi delimitada utilizando dados do sensor SRTM (Shuttle Radar Topography Mission) e técnicas de geoprocessamento. Após a delimitação da bacia, foram extraídos os seguintes aspectos: geologia, geomorfologia, os solos e vegetação. Para a caracterização dos dados, primeiramente, foram utilizadas imagens SRTM no formato geotiff, oriundos da base de dados USGS (United States Geological Survey). Os dados referentes as características ambientais que abrangem a área da Bacia Hidrográfica foram obtidas através do IBGE e CPRM (Companhia de Pesquisa de Recursos Minerais), onde foram gerados mapas individuais dos aspectos estudados pelo sistema de informações geográficas.

\section{Resultados e Discussão}

Os resultados mostraram que a área da bacia do Rio Munin abrange uma área de $15.817,4 \mathrm{~km}^{2}$. A geomorfologia do local apresenta uma diversidade de formas separadas em sete unidades, com a predominância do Panamá do Rio Itapecuru e Tabuleiros Costeiros. O solo apresentou uma variedade de sete tipos de solos, com predominância do Plintossolo Pétrico e Concrecionário Distrófico. A vegetação na região apresentou um total de onze tipos, com predominância da Savana/ Floresta Estacional, Vegetação Secundária e Atividades Agrárias. A geologia apresentou uma diversidade que totalizou onze unidades, com a predominância de Itapecuru.

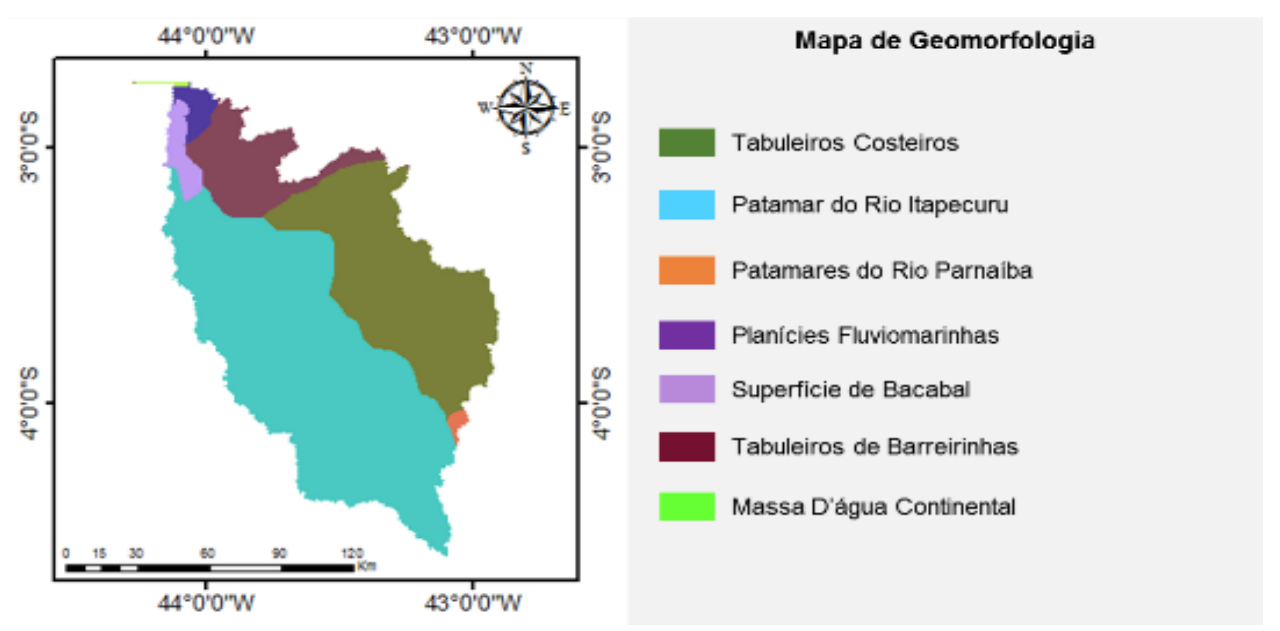

Fig.1 - Mapa de Geomorfologia

A figura 1 apresenta a geomorfologia da bacia do Rio Munin, com predominância em Patamar do Rio Itapecuru e Tabuleiros Costeiros. De acordo com a 
JACOB (2014), a geomorfologia fornece informações importantes sobre a forma e os processos físicos atuantes no sistema fluvial de uma bacia. O movimento de sedimentos dentro de bacias hidrográficas e, principalmente, dentro do canal e da planície de inundação constitui a geomorfologia fluvial. A morfologia, ou seja, as formas e estruturas dos organismos vegetais do canal e das planícies de inundação são resultado do movimento e armazenamento dos sedimentos. Logo a geomorfologia é uma importante para auxiliar o ser humano a ocupar e utilizar o meio natural de maneira correta, de modo a minimizar os impactos gerados sobre a natureza.

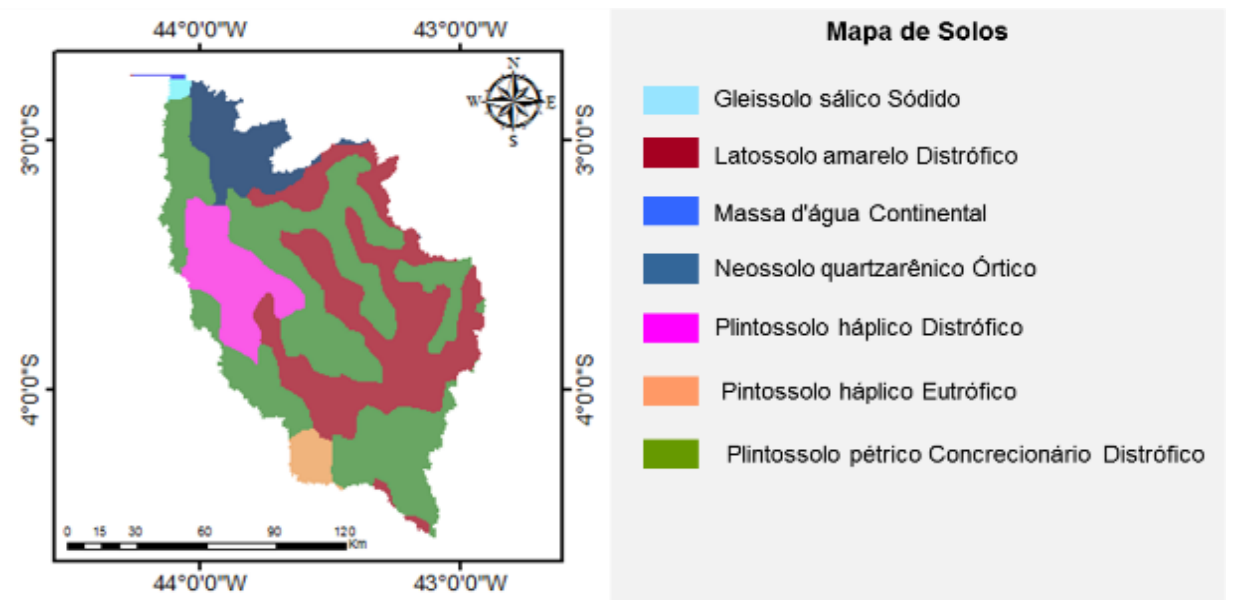

Fig.2 - Mapa dos Solos

A figura 2 mostra a predominância do solo tipo Plintossolo Pétrico Concrecionário Distrófico. Segundo a AGEITEC (Agência Embrapa de Informação Tecnológica), esse tipo de solo é caracterizado pela presença de plintita endurecida e consolidada, que são camadas constituídas pela mistura de material de argila, e rica em ferro ou ferro e alumínio, com grãos de quartzo e outros minerais. Por ser muito pobre em carbono orgânico, sua presença no solo indica drenagem imperfeita compondo um sério obstáculo à penetração de raízes e aos trabalhos de preparo do solo. Devido a suas restrições ao uso agrícolas e o pouco volume de solo disponível as plantas, é muito comum o uso desse solo para pastagens. 

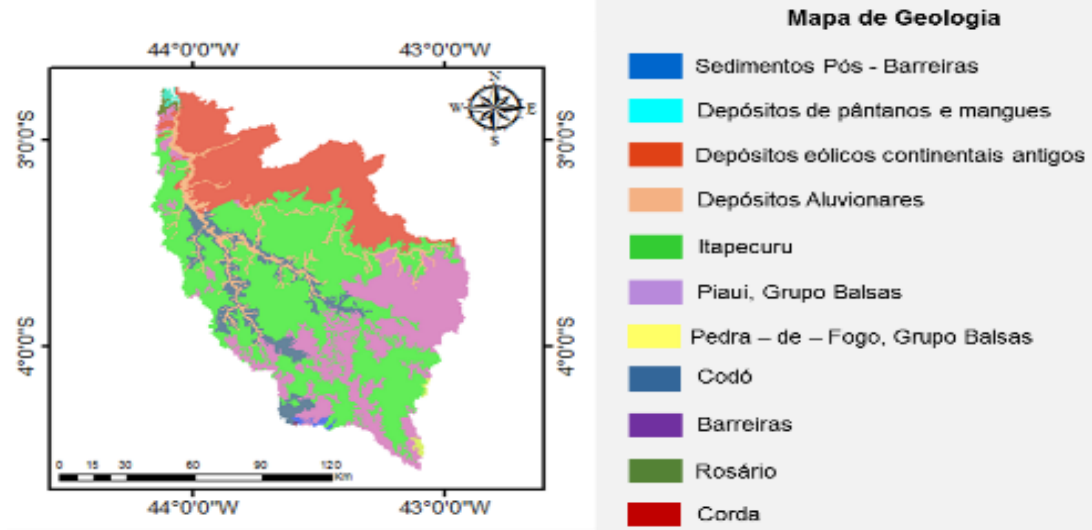

Fig.4 - Mapa de Geologia

A figura 4 mostra a predominância geológica do tipo Itapecuru, Antoneli \& Thomaz (2007) ressaltam que o estudo de aspectos referentes à geologia, pode levar à resolução e compreensão de diversas aspectos associados à dinâmica ambiental da bacia hidrográfica. Dessa forma é necessário considerar que se trata de um aspecto na qual suas características e os processos são estreitamente interdependentes, de tal maneira que qualquer ação antrópica que venha a ocorrer em determinado ponto da bacia hidrográfica, pode produzir inevitavelmente um ajustamento do sistema de drenagem.
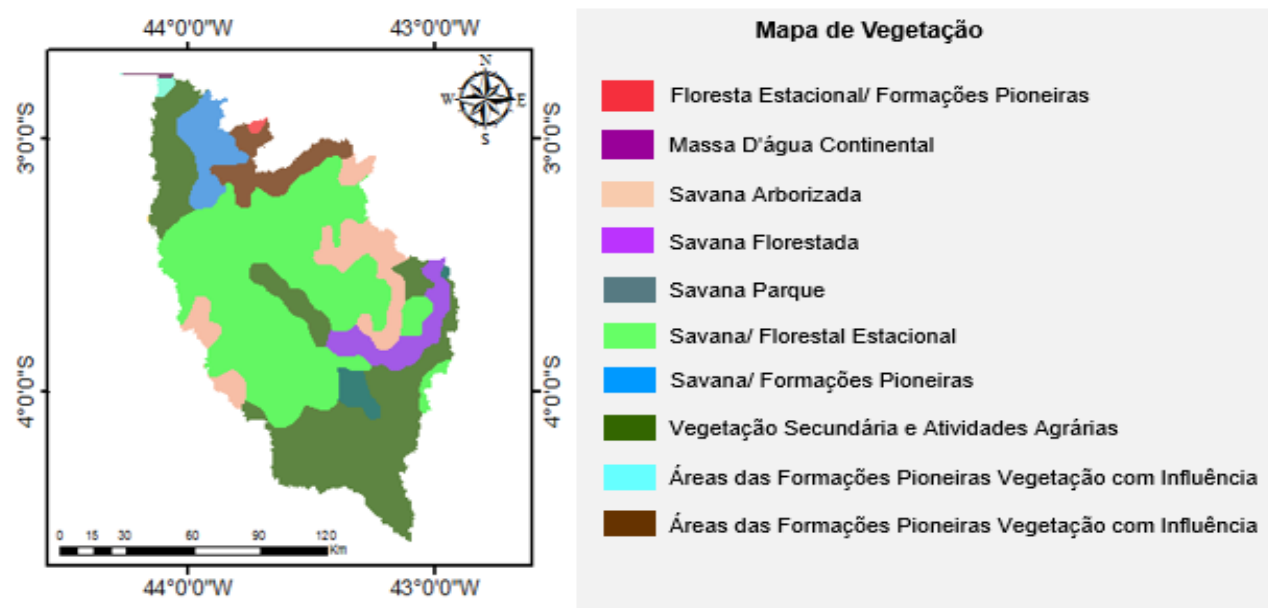

Fig.3 - Mapa de Vegetação

A figura 3 apresenta os tipos de vegetação com predominância da Savana/Florestal Estacional. Segundo Santos et al. (2010) a identificação da vegetação da área de uma bacia hidrográfica permite conhecimento dos seus tipos de paisagem natural para o correto manejo e uso, que dependendo da situação local as torna mais vulneráveis aos processos erosivos, proporcionando modificações no padrão da vegetação típico da região de uma bacia hidrográfica.

\section{Conclusão}

Os aspectos de geomorfologia, solos, geologia e vegetação encontrados possibilitaram uma caracterização ambiental geral da Bacia Hidrográfica do Rio Munim, gerando 
dados relevantes para que sirvam de base para o conhecimento e o exame situacional do ambiente, sendo a bacia hidrográfica uma unidade territorial para implementação da política nacional de recursos hídricos e a atuação do sistema nacional de gerenciamento de recursos hídricos tomar decisões para prevenção, controle e correção de problemas ambientais é fundamental para manutenção do ecossistema.

\section{Referências}

GARCEZ, Lucas Nogueira; ALVAREZ, Guillermo Acosta. Hidrologia. 2. ed. São Paulo: Edgard Blucher, 1988.

FLORENZANO, Teresa Gallotti. Iniciação em Sensoriamento Remoto. 3.ed. São Paulo: Oficina de texto, 2011.

MORAES, Evlyn M.L. Sensoriamento Remoto: Princípios e Aplicações. 4.ed. São Paulo: $\quad$ Edgard Blucher, 2010.

Situação Ambiental na Região do Baixo Munim/ Instituto Maranhense de Estudos Socioeconômicos e Cartográficos - São Luís: IMESC, 2012

ALAGOAS. (2008)Secretaria de meio ambiente e recursos hídricos/superintendência de infraestrutura hídrica. Plano estadual: programa água doce. Jan/2009 a Dez/2010 p.73-74.

REYMÃO, A. E. e SABER, B. A (2009). Acesso a água tratada e a insuficiência de renda: duas dimensões do problema da pobreza no nordeste brasileiro sob a óptica dos objetivos de desenvolvimento do milênio. Revista Iberoamericana de Economia Ecológica. v. 12: p. 1-15.

AQUAFLUXUS. A Geomorfologia Fluvial e Sua Importância no Estudo dos Cursos D'água. Postado por Ana Caroline Pitzer Jacob. Disponível em: http://www.aquafluxus.com.br/a-geomorfologia-fluvial-e-sua-importancia-no-estudodos-cursos-dagua/. Acesso em: 19 de maio de 2017.

AGEITEC. Solos Tropicais: Plintossolo Pétrico. Disponível em: http://www.agencia.cnptia.embrapa.br/gestor/solos_tropicais/arvore/CONT000gn362ja2 02wx5ok0liq1mqrdmmd4k.html. Acesso em: 20 de maio de 2017.

ANTONELI, V; Thomaz, E. L. Caracterização do meio físico da bacia do Arroio Boa Vista, Guamiranga-PR. Revista Caminhos da Geografia, v.8, p.46-58, 2007.

SANTOS, E. H. M.; GRIEBELER, N. P.; OLIVEIRA, L. F. C. Relação entre uso do solo e comportamento hidrológico na Bacia Hidrográfica do Ribeirão João Leite. Revista Brasileira de Engenharia Agrícola e Ambiental, v.14, p.826-834, 2010.

BRASIL. Lei n. 9.433, de 8 de janeiro de 1997. Disponível em: <http://www2.camara.leg.br/legin/fed/lei/1997/lei-9433-8-janeiro-1997-374778-normapl.html>. Acesso em: 10 out. 2013. 